\title{
Fault Tolerant Control of Robot Manipulators Based on Adaptive Fuzzy Type-2 Backstepping in Attendance of Payload Variation
}

\author{
Hilal Rahali $^{1 *} \quad$ Samir Zeghlache $^{2} \quad$ Loutfi Benyettou $^{1}$ \\ ${ }^{1}$ Laboratoire de genie élecrtique, Department of Electrical Engineering, \\ University Mohamed Boudiaf of M'sila, Algeria \\ ${ }^{2}$ Laboratoire d'analyse des signaux et systèmes, Department of Electrical Engineering, \\ University Mohamed Boudiaf of M'sila, Algeria \\ * Corresponding author's Email: hilal.rahali@univ-msila.dz
}

\begin{abstract}
In this study, an adaptive fuzzy type-2 backstepping controller (AFT2BC) has been proposed for an industrial PUMA560 manipulator robot with a variable load and actuator faults. The method realizes an accurate tracking of the trajectory at the end effectors of the manipulator and improves its robustness toward model uncertainty (payload variation) and actuator faults when controlling the position of the robot. By using the advantages of the backstepping control, the convergence speed of the control algorithm has been improved, and its steady-state error has been reduced. Also, integration of the continuous approximation law has been used to eliminate the real-time chattering during the control process without affecting the robustness of the system. A type-2 fuzzy adaptive control law has been designed in order to guaranty faults and uncertainties compensation, small tracking error, and fast transient response, where the prior knowledge of uncertainties and external disturbances is not required, without disappearing the tracking precision and robustness property. Finally, the stability of the controller has been proved by the Lyapunov theory, and comparative simulations in faulty operation are conducted to show the superiority of the developed control strategy.
\end{abstract}

Keywords: Fault tolerant control, Adaptive fuzzy type-2, Backstepping, PUMA560 robot, Payload variation.

\section{Introduction}

In recent years, robotic manipulator becomes very important in several sophisticated industrial applications such as painting, drilling, and welding, it has acquired wide concern in reason to the great performance in these tasks needing high precision for path following.

The control of robot manipulators is a very hard mission because this type of system is characterized by highly nonlinearities; coupling effects, uncertainties, and external disturbances [1]. Efforts were made to deal with these problems, like PID control, fuzzy logic control [3], neural network control [4], feedback linearization control [5], predictive control [6], sliding mode control [8-10], and backstepping control [11] has been adapted to the pursuit missions of manipulators robot. Sliding mode control is an efficient nonlinear robust control method because it furnishes system dynamics with robustness behavior to external disturbances and uncertainties as soon as the system dynamics are driven in the sliding surface [12, 13]. In [14] a robust sliding mode control based on a linear PID sliding surface has been developed to the robot manipulator, this control strategy can handle bounded parameter uncertainties and external disturbances. A first-order sliding mode controller for a two-link robot manipulator has been designed in [15]. Terminal sliding mode control by using nonlinear sliding surfaces has been proposed in [16] so that to reach finite time convergence without providing a high control input. In [17, 18] proposed fast nonsingular terminal sliding mode control for manipulator robots to minimize the convergence speed. Nevertheless, the sliding mode control contains a switching expression that leads to the chattering phenomenon, which will probably produce high frequency in the control 
signals, actuator destruction, and great energy consumption.

Recently, several solutions have been proposed in the literature in order to reduce the chattering phenomena such as the authors in [19] have utilized the boundary layer method, where the discontinuous sign function is replaced by sigmoid function or saturation function. But this solution demeans the robustness and the performances. That is why other effective techniques have been suggested for instance in $[20,21]$, where the authors have adopted highorder sliding mode control by introducing twisting and super-twisting algorithms. Another solution based on second-order sliding mode has been proposed in [22, 23]. The backstepping approach furnishes a methodical closed-loop construction instrument of Lyapunov function to a wide class of non-linear systems. Owing to its easy configuration, this control method is extensively used in robotic manipulator systems, such as in [24] a robust backstepping control has applied to the planar freefloating space robot with dual-arms. The results prove the efficiency of the developed control strategy.

A hybrid non-linear control using adaptive methods is an effective control technique for uncertain dynamic systems such as robotic manipulators... In [25], it introduces a robust fast non singular terminal sliding mode control with parameter adaptation in order to stabilize the position and velocity errors of 2-DOF manipulator robot towards zero in finite time. An adaptive second-order terminal sliding mode approach is developed in [26] to obtain a better tracking of the desired trajectory with the elimination of chattering phenomenon. Another adaptive control strategy proposed in [27] based on second-order fast nonsingular terminal sliding mode where all uncertainties existing in 2DOF manipulator robot are dominated by adopting the adaptive approach. In addition, a prior acquaintance of the upper bound of uncertainties is not needed. In [28] an adaptive backstepping control technique is introduced for path following of manipulator robot in the existence of external disturbances and uncertainties. An Adaptive fuzzy sliding mode control has been proposed in [29] for 3 DOF planar robot manipulators, where the authors used a type-1 fuzzy logic system to produce the discontinuous control. In addition, the output gain is adapted on-line by a supervisory fuzzy inference system in order to avoid the chattering effects. The stability in the closed-loop is proved by using Lyapunov theorem. In [30] the authors suggest the backstepping adaptive fuzzy control method for three-link robot manipulators to obtain the tracking errors tends to zero in finite time.
An adaptive fuzzy controller for robotic manipulator has been designed in [31], this control scheme can compensate the modeling errors and external disturbances, the simulation results illustrate powerful robustness and better precision. The majority of precedent research works assume that robotic manipulator systems are in healthy condition. Consequently, the motivation of this paper is to provide a robust fault tolerant control based on the backstepping approach and adaptive fuzzy type-2 for the path following problem of 3-DOF robotic manipulator with variable payload.

An adaptive fuzzy type-2 backstepping control method is studied in this paper, which is suitable for nonlinear systems with uncertainties (payload variation) and actuator faults [32-35].

The advantage of the proposed control method is to compensate all the uncertainties at the same time and avoid the inherent "explosion of complexity" problem. By introducing special adjustable control parameters, not only the control precision of the system is greatly improved, and the initial control input is significantly reduced [32].

The main contributions of the proposed control method are highlighted as follows:

- Compared to the passive fault tolerant control designed in $[36,37]$ which requests to acquaint or to identify the faults. This control scheme becomes very hard in case of complex faults. In this paper, the proposed controller needs an adaptive fuzzy type- 2 system in order to obtain a robust estimation of uncertainties and faults.

- The proposed adaptive fault tolerant control contains a robust term with adaptive gain that allows to having more robustness against uncertainties and faults which give certain superiorities compared to [29, 31], which are based on traditional adaptive fuzzy control for the robotic manipulator.

- In [38, 39] authors adopt a complicated fault tolerant control based on observer for estimate faults. Unfortunately, this method needs an additional observer, which will augment computational time, which is not desired for realtime implementation. In this work, an adaptive fault tolerant control scheme does not require an observer or diagnostic block.

- A novel PID-nonsingular fast terminal sliding mode control has been used in [40], in order to give a robust fault tolerant control of robot manipulators. In addition, the time delay estimation is introduced to approximate the unknown dynamics model, despite good obtained results, but this approach is very complicated 
compared to the proposed work, where the unknown dynamics model is estimated directly by the adaptive fuzzy type- 2 system without needing delay time estimation.

- Contrary to [30], the adaptive control approach introduced in this work has been performed in all stages of the backstepping algorithm synthesis deals with a 3-DOF manipulator robot in defective operation. On the other hand in [30], a sane 3DOF manipulator robot condition is taken into account. On the other hand in [30], a sane 3-DOF manipulator robot condition is taken into account.

- Fuzzy logic control has been used widely to control manipulator robots in diverse papers such as [41-44]. Nevertheless, the trial and error conduct to the considerable limitation of these techniques [45]. In [46] an optimized fuzzy type2 PID controller is designed to control robotic manipulator with variable payload, to reach path following, and to minimize the effects of the external disturbances; but it can't handle defects. On the other hand, in this work, an adaptive fuzzy type-2 control is developed in order to obtain a better path following with variable payload and actuator faults.

- Adaptive control concerns the online adjustment of the control loop regulators in order to guarantee a certain level of performance. Several recent works have used this approach to control manipulators robot $[19,25,28,47,48]$, this technique proved fast and unaffected to external disturbances, where no exact model is required. Although, the fault effects are not taken into consideration. In this paper, hybrid adaptive control based on backstepping, and the fuzzy type-2 system is developed like a fault tolerant control with the existence of external disturbances, actuator defects, and uncertainties.

In order to prove the efficiency of the proposed approach (AFT2BC), simulations are effectuated in the MATLAB programming environment to the 3DOF robot manipulators dynamical model. The proposed control method allows us to avoid the modeling problems, to provide a low tracking errors and the best robustness versus payload variations and actuator faults effects. The contributions of this paper can be summarized as:

- Non-linear adaptive control method is introduced in this paper to the 3-DOF robot manipulators in order to give robust tracking in the existence of uncertainties such as payload variations and actuator faults in the same time. In addition, the proposed control does not need the knowledge of the dynamical model.
- The proposed control is introduced to the $3-\mathrm{DOF}$ robot manipulators in its perfect non linear model with coupling effects in which the decoupling stage doesn't need in control design.

The remainder of this paper is arranged as follows, In Section 2, the dynamical model of the robot in the healthy and faulty condition is presented. Section 3 presents the robust fault tolerant control using adaptive fuzzy type-2 backstepping. Simulations results and discussion are given in Section 4. Section 5 presents a quantitative comparison. Conclusions are summarized in Section 6.

\section{Dynamic model of robot manipulator}

\subsection{Dynamic model of robot manipulator in healthy condition}

The PUMA 560 robots is a three DOF robot arm, this type of robot is widely used in industry. Figure.1 shows the configuration of PUMA 560 robots.

The dynamic model of the PUMA 560 is given by [45]:

$$
M(q) \ddot{q}+V_{m}(q, \dot{q}) \dot{q}+G(q)+u_{m 0}=u
$$

where $u=\left[\begin{array}{lll}u_{1} & u_{2} & u_{3}\end{array}\right]^{T}$ is the joint input torque vector, $q=\left[q_{1} q_{2} q_{3}\right]^{T}$ is the joint position vector, $\dot{q}=\left[\dot{q}_{1} \dot{q}_{2} \dot{q}_{3}\right]^{T}$ is the joint velocity vector, $\dot{q}=$ $\left[\ddot{q}_{1} \ddot{q}_{2} \ddot{q}_{3}\right]^{T}, M(q)$ is symmetric positive definite matrix of inertial accelerations, $V_{m}(q, \dot{q})$ is the matrix of coriolis and centrifugal forces, $G(q)$ is state varying vector of gravity terms. $M(q), V_{m}(q, \dot{q})$ and $G(q)$ are given in Appendix A, and $u_{m 0}$ is the vector of torque due to the payload $m_{0}$ determined by [49]:

$$
u_{m 0}=m_{0} J^{T}(q)[J(q) \ddot{q}+\dot{J}(q, \dot{q}) \dot{q}+g]
$$

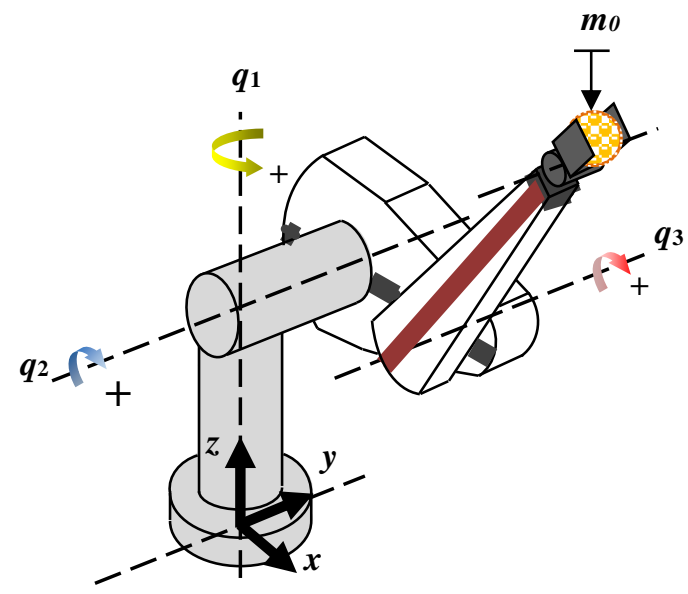

Figure. 1 PUMA 560 robot configuration [49] 
With: $g=\left[\begin{array}{lll}0 & 0 & 9.81\end{array}\right]^{T}$ and $J$ is Jacobian matrix determined in Appendix A.

Eq. (1) can be rearranged by:

$$
\begin{array}{r}
\ddot{q}=\left[M(q)+m_{0} J^{T}(q) J(q)\right]^{-1}\left[u-V_{m}(q, \dot{q}) \dot{q}-\right. \\
\left.G(q)-m_{0} J^{T}(q) j(q, \dot{q}) \dot{q}-m_{0} J^{T}(q) g\right]
\end{array}
$$

\subsection{Dynamic model of robot manipulator in faulty condition}

In robotic manipulators, failure in the actuators can be engendered by several causes such as failure in power supply systems. The dynamic model of robot manipulator in faulty operation is obtained by:

$$
\begin{gathered}
\ddot{q}=\left[M(q)+m_{0} J^{T}(q) J(q)\right]^{-1}\left[u_{f}-V_{m}(q, \dot{q}) \dot{q}-\right. \\
\left.G(q)-m_{0} J^{T}(q) \dot{j}(q, \dot{q}) \dot{q}-m_{0} J^{T}(q) g\right]
\end{gathered}
$$

Where:

$$
u_{f}=u+U_{0}
$$

$U_{0}$ is unknown function related to the actuator faults. Introducing Eq. (5) into Eq. (4), the dynamic model in Eq. (3) becomes:

$$
\begin{array}{r}
\ddot{q}=\left[M(q)+m_{0} J^{T}(q) J(q)\right]^{-1}\left[u-V_{m}(q, \dot{q}) \dot{q}-\right. \\
\left.G(q)-G(q)-m_{0} J^{T}(q) \dot{J}(q, \dot{q}) \dot{q}-m_{0} J^{T}(q) g\right]+ \\
\vartheta(q, \dot{q}, u)
\end{array}
$$

With: $\vartheta(q, \dot{q}, u)=\left[M(q)+m_{0} J^{T}(q) J(q)\right]^{-1} U_{0}$

\section{Robust fault tolerant control design}

The dynamic model Eq. (6) can be rewritten in the state space as:

If $M(q), V_{m}(q, \dot{q})$ and $G(q)$ are known and free of payload uncertainties and actuator faults, i.e., $U_{0}$ the state space presentation of the PUMA 560 robot is obtained as:

$$
\left\{\begin{array}{l}
\dot{x}_{1}=x_{2} \\
\dot{x}_{2}=[M(q)]^{-1}\left[u-V_{m}(q, \dot{q}) \dot{q}-G(q)\right] \\
y=x_{1}
\end{array}\right.
$$

Where $x_{1}=\left[q_{1} q_{2} q_{3}\right]^{T}$ is the state vector, $x_{2}=$ $\left[\dot{q}_{1} \dot{q}_{2} \dot{q}_{3}\right]^{T}$

The tracking error variable is defined by:

$$
e_{1}=q_{d}-x_{1}
$$

Where $q_{d}=\left[q_{1 d} q_{2 d} q_{3 d}\right]^{T}$ is desired signal.
A Lyapunov function is defined as follows:

$$
V_{1}=\frac{1}{2} e_{1}^{2}
$$

The time derivative of Eq. (11) is computed by:

$$
\dot{V}_{1}=e_{1} \dot{e}_{1}=e_{1}\left(\dot{q}_{d}-x_{2}\right)
$$

The virtual control law $\beta_{2}$ is obtained by:

$$
\beta_{2}=\dot{q}_{d}+c_{1} e_{1}
$$

Where $c_{1} \in \Re^{3}$ is positive constant vector.

\section{Step 2}

In this step the tracking error variable is given as:

$$
e_{2}=\beta_{2}-x_{2}=\dot{q}_{d}+c_{1} e_{1}-x_{2}
$$

The time derivative of $e_{1}, e_{2}$ are computed by:

$$
\left\{\begin{array}{c}
\dot{e}_{1}=e_{2}-c_{1} e_{1} \\
\dot{e}_{2}=\ddot{q}_{d}+c_{1}\left(e_{2}-c_{1} e_{1}\right)-[M(q)]^{-1}[u- \\
\left.V_{m}(q, \dot{q}) \dot{q}-G(q)\right]
\end{array}\right.
$$

Let define the augmented Lyapunov function:

$$
V_{2}=\frac{1}{2} e_{1}^{2}+\frac{1}{2}[M(q)] e_{2}^{2}
$$

The time derivative of Eq. (14) is given as:

$$
\dot{V}_{2}=e_{1} \dot{e}_{1}+[M(q)] e_{2} \dot{e}_{2}-\frac{1}{2}[\dot{M}(q)]^{-1}[M(q)]^{2} e_{2}^{2}
$$

Introducing Eq. (13) into Eq. (15) yields:

$\dot{V}_{2}=-c_{1} e_{1}^{2}+e_{2}$

$\left(\frac{\ddot{q}_{d}+c_{1}\left(e_{2}-c_{1} e_{1}\right)-[M(q)]^{-1}\left[u-V_{m}(q, \dot{q}) \dot{q}-G(q)\right]}{[M(q)]^{-1}}-\right.$

$\left.\frac{1}{2}[\dot{M}(q)]^{-1}[M(q)]^{2} e_{2}-u\right)$

The control law $u$ is obtained by:

$u=\frac{1}{[M(q)]^{-1}}\left(\ddot{q}_{d}+c_{1}\left(e_{2}-c_{1} e_{1}\right)+\right.$

$[M(q)]^{-1}\left[V_{m}(q, \dot{q}) \dot{q}+G(q)\right]-$

$\left.\frac{1}{2}[\dot{M}(q)]^{-1}[M(q)]^{2} e_{2}\right)+c_{2} e_{2}$

Where $c_{2} \in \mathfrak{R}^{3}$ is positive constant vector.

Using Eq. (17), it can be cheeked that:

$$
\dot{V}_{2} \leq-c_{1} e_{1}^{2}-c_{2} e_{2}^{2}
$$




$$
\dot{V}_{2}<0
$$

The functions $M(q), V_{m}(q, \dot{q})$ and $G(q)$ are unknown and $\vartheta(q, \dot{q}, u)$ term which include payload variations and actuator faults effects are different to zero $\left(U_{0} \neq\right.$ 0 and $m_{0} \neq 0$ ), in this paper adaptive type fuzzy- 2 fuzzy system has been used to deal this problem. The proposed approach concern the online estimation of the ideal control law obtained by backstepping method using fuzzy type-2 inference system where the fuzzy parameters are adjusted by adaptive laws.

The ideal control law presented in Eq. (17) can be rewritten in the following form [50]:

$$
u=u_{b}+c_{2} e_{2}
$$

With:

$$
\begin{gathered}
u_{b}=\frac{1}{[M(q)]^{-1}}\left(\ddot{q}_{d}+c_{1}\left(e_{2}-c_{1} e_{1}\right)+[M(q)]^{-1}\right. \\
\left.\left[V_{m}(q, \dot{q}) \dot{q}+G(q)\right]-\frac{1}{2}[\dot{M}(q)]^{-1}[M(q)] e_{2}\right)(21)
\end{gathered}
$$

The fuzzy type- 2 inference system is principally utilized to estimate the control laws $u_{b, j}$ in Eq. (21) by:

$$
\widehat{u}_{b}=W^{T}\left(e_{1}, \dot{e}_{1}\right) \Theta
$$

Where $\Theta$ denotes adapted vector parameters, and $W^{T}(X)$ represents average basis functions obtained by fuzzy type-2 system where each basis function is given by the average of corresponded left and right basis functions. forms:

The real $u_{b}$ can be expressed in the following

$$
u_{b}=W^{T}\left(e_{1}, \dot{e}_{1}\right) \Theta^{*}+\varepsilon
$$

Where $\Theta^{*}$ are the optimal parameters, and $\varepsilon$ are the estimation errors that satisfy the condition: $|\varepsilon| \leq \bar{\varepsilon}$ Where $\bar{\varepsilon}$ is unknown positive parameter.

The adaptive control laws applied to the robot is given by [50]:

$$
u=u_{a}+u_{r}+u_{p}
$$

With:

1. $u_{a}$ is the fuzzy type-2 adaptive control expression which is designed in order to estimate the ideal backstepping control law $u_{b}$ in Eq. (21) given as:

$$
u_{a}=\hat{u}_{b}=W^{T}\left(e_{1}, \dot{e}_{1}\right) \Theta
$$

Where $W^{T}(X)$ denotes average basis functions obtained by fuzzy type- 2 system where each basis function is given by the average of corresponded left and right basis functions and $\Theta$ is the adapted vector parameters given by:

$$
\dot{\Theta}=\gamma e_{2}, W\left(e_{1}, \dot{e}_{1}\right)-\sigma_{1} \Theta
$$

Where $\gamma>0$ and $\sigma_{1}>0, e_{2}=\dot{q}_{d}+c_{1} e_{1}-$ $x_{2}$ and $\Theta(0)=0$.

2. $u_{r}$ is robust control expressions are introduced to reduce both the effects of fuzzy type-2 estimation error and uncertainties determined by [51]:

$$
u_{r}=\hat{\varepsilon} \tanh \left(\frac{e_{2}}{\chi}\right)
$$

$$
\dot{\hat{\varepsilon}}=\eta \hat{e}_{2} \tanh \left(\frac{e_{2}}{\chi}\right)-\sigma_{2} \hat{\varepsilon}
$$

With $\eta>0, \sigma_{2}>0, \chi>0$ and $\hat{\varepsilon}(0)=0$.

3. $u_{p}$ are given by:

$$
u_{p}=c_{2} e_{2}
$$

Where $c_{2}>0$.

\subsection{Stability Analysis}

Define the following Lyapunov functions:

$$
V=\frac{1}{2} e_{1}^{2}+\frac{1}{2}[M(q)] e_{2}^{2}+\frac{1}{2 \gamma} \tilde{\Theta}^{T} \tilde{\Theta}+\frac{1}{2 \eta} \tilde{\varepsilon}^{T} \tilde{\varepsilon}
$$

$\tilde{\varepsilon}$ and $\widetilde{\Theta}$ are the estimation errors defined by:

$$
\tilde{\varepsilon}=\varepsilon^{*}-\hat{\varepsilon}
$$

$\hat{\varepsilon}$ is the estimate of $\varepsilon^{*}$

$$
\widetilde{\Theta}=\Theta^{*}-\Theta
$$

The time derivative of Eq. (30) yields:

$$
\dot{V}=-c_{1} e_{1}^{2}+e_{2}\left(u_{b}-u\right)+\frac{1}{\gamma} \tilde{\Theta}^{T} \dot{\tilde{\Theta}}+\frac{1}{\eta} \tilde{\varepsilon}^{T} \dot{\tilde{\varepsilon}}
$$

Substituting Eqs. (23-25), and (29) in Eq. (33) yields:

$$
\begin{aligned}
& \dot{V} \leq-c_{1} e_{1}^{2}+e_{2}\left(W^{T}\left(e_{1}, \dot{e}_{1}\right) \Theta^{*}+\right. \\
& \left.\varepsilon-W^{T}\left(e_{1}, \dot{e}_{1}\right) \Theta-u_{r}-c_{2} e_{2}\right)+\frac{1}{\gamma} \widetilde{\Theta}^{T} \dot{\tilde{\Theta}}+\frac{1}{\eta} \tilde{\varepsilon}^{T} \dot{\tilde{\varepsilon}}
\end{aligned}
$$

The optimal parameters vector $\Theta^{*}$ and $\varepsilon_{j}^{*}$ are slowly time varying, therefore the time derivative of estimation error will be: 


$$
\dot{\tilde{\varepsilon}}=-\dot{\hat{\varepsilon}} \text { and } \dot{\tilde{\Theta}}=-\dot{\Theta}
$$

Substituting Eq. (34) in Eq. (35) and taking account Eq. (32) we obtain:

$$
\begin{gathered}
\dot{V} \leq-c_{1} e_{1}^{2}-c_{2} e_{2}^{2}+e_{2} W^{T}\left(e_{1}, \dot{e}_{1}\right) \tilde{\Theta}+ \\
e_{2}\left(\varepsilon-u_{r}\right)-\frac{1}{\gamma} \widetilde{\Theta}^{T} \dot{\Theta}-\frac{1}{\eta_{j}} \tilde{\varepsilon}_{j}^{T} \hat{\hat{\varepsilon}}_{j}
\end{gathered}
$$

By introducing Eqs. (26) and (28) into Eq. (36), yield:

$$
\begin{gathered}
\dot{V} \leq-c_{1} e_{1}^{2}-c_{2} e_{2}^{2}+e_{2}\left(\varepsilon-u_{r,}\right)+\frac{\sigma_{1}}{\gamma} \tilde{\Theta}^{T} \Theta- \\
\frac{1}{\eta} \tilde{\varepsilon} \eta e_{2} \tanh \left(\frac{e_{2}}{\chi}\right)+\frac{\sigma_{2}}{\eta} \tilde{\varepsilon} \hat{\varepsilon}
\end{gathered}
$$

Substituting Eq. (31) in Eq. (37) we obtain:

$$
\begin{gathered}
\dot{V} \leq-c_{1} e_{1}^{2}-c_{2} e_{2}^{2}+e_{2}\left(\varepsilon-u_{r}\right) \frac{\sigma_{1}}{\gamma} \tilde{\Theta}^{T} \Theta- \\
\varepsilon^{*} e_{2} \tanh \left(\frac{e_{2}}{\chi}\right)+\hat{\varepsilon} e_{2} \tanh \left(\frac{e_{2}}{\chi}\right)+\frac{\sigma_{2}}{\eta} \tilde{\varepsilon} \hat{\varepsilon}
\end{gathered}
$$

Or equivalently:

$\dot{V} \leq-c_{1} e_{1}^{2}-c_{2} e_{2}^{2}+\frac{\sigma_{1}}{\gamma} \widetilde{\Theta}^{T} \Theta-\varepsilon^{*} e_{2} \tanh \left(\frac{e_{2}}{\chi}\right)+$

$\hat{\varepsilon} e_{2} \tanh \left(\frac{e_{2}}{\chi}\right)+\frac{\sigma_{2}}{\eta} \tilde{\varepsilon} \hat{\varepsilon}-e_{2}, u_{r}+\left|e_{2}\right| \varepsilon^{*}$

By introducing Eq. (27) into Eq. (39), yields:

$$
\begin{gathered}
\dot{V} \leq-c_{1} e_{1}^{2}-c_{2} e_{2}^{2}+\frac{\sigma_{1}}{\gamma} \tilde{\Theta}^{T} \Theta+\left|e_{2}\right| \varepsilon^{*}- \\
\varepsilon^{*} e_{2} \tanh \left(\frac{e_{2}}{\chi}\right)+\frac{\sigma_{2}}{\eta} \tilde{\varepsilon} \hat{\varepsilon}
\end{gathered}
$$

Consider the inequality written as follows for any value of $\zeta>0$ [51]:

$$
\left|e_{2}\right|-e_{2} \tanh \left(\frac{e_{2}}{\chi}\right) \leq \zeta \chi=\varsigma
$$

With $\zeta$ is a constant equal $\zeta=0.2785$.

Eq. (41) is changed as follows:

$$
\dot{V} \leq-c_{1} \hat{e}_{1}^{2}-c_{2} \hat{e}_{2}^{2}+\varepsilon^{*} \varsigma+\frac{\sigma_{1}}{\gamma} \widetilde{\Theta}^{T} \Theta+\frac{\sigma_{2}}{\eta} \tilde{\varepsilon} \hat{\varepsilon}
$$

By utilizing young's inequality, one has:

$$
\begin{gathered}
\frac{\sigma_{1}}{\gamma} \tilde{\Theta}^{T} \Theta \leq-\frac{\sigma_{1}}{2 \gamma} \tilde{\Theta}^{T} \Theta+\frac{\sigma_{1}}{2 \gamma} \tilde{\Theta}^{* T} \Theta^{*} \\
\frac{\sigma_{2}}{\eta} \tilde{\varepsilon}^{T} \hat{\varepsilon} \leq-\frac{\sigma_{2}}{2 \eta} \tilde{\varepsilon}^{2}+\frac{\sigma_{2}}{2 \eta}\left|\varepsilon^{*}\right|^{2}
\end{gathered}
$$

By introducing Eqs. (43) and (44) into Eq. (42), yields:

$$
\begin{gathered}
\dot{V} \leq-c_{1} e_{1}^{2}-c_{2} e_{2}^{2}+\varepsilon^{*} \varsigma-\frac{\sigma_{1}}{2 \gamma} \tilde{\Theta}^{T} \Theta+ \\
\frac{\sigma_{1}}{2 \gamma} \tilde{\Theta}^{* T} \Theta^{*}-\frac{\sigma_{2}}{2 \eta} \tilde{\varepsilon}^{2}+\frac{\sigma_{2}}{2 \eta}\left|\varepsilon^{*}\right|^{2}
\end{gathered}
$$

Let's specify:

$$
c=\min \left\{\sigma_{1}, \sigma_{2}, 2 c_{1}, 2 c_{2}\right\}
$$

Eq. (45) becomes:

$$
\dot{V} \leq-c V+\rho
$$

With:

$$
\rho=\varepsilon^{*} \varsigma+\frac{\sigma_{1}}{2 \gamma} \tilde{\Theta}^{* T} \Theta^{*}+\frac{\sigma_{2}}{2 \eta}\left|\varepsilon^{*}\right|^{2}
$$

By Integrating Eq. (48), yields:

$$
V(t) \leq V(0) e^{-c t}+\frac{\rho}{c}
$$

From Eq. (47) it can be proved that the proposed control law of PUMA 560 robot presented in Eq. (24) is asymptotically stable despite the presence payload uncertainties and actuator faults consequently the tracking errors converge to zero, which gives full demonstration. The proposed control scheme is given in Figure 2.

\section{Simulation results}

The proposed control strategy has been effectuated by simulation using MATLAB/Simulink in order to verify the effectiveness and the capability attained for the tracking performances of the three joints. The physical parameters PUMA 560 robot is given in appendix A.

Two simulation testes of the PUMA 560 robot are carried out, where payload uncertainties and actuator faults are taken in consideration. In Test 1 , the three joints of PUMA 560 robot are commanded

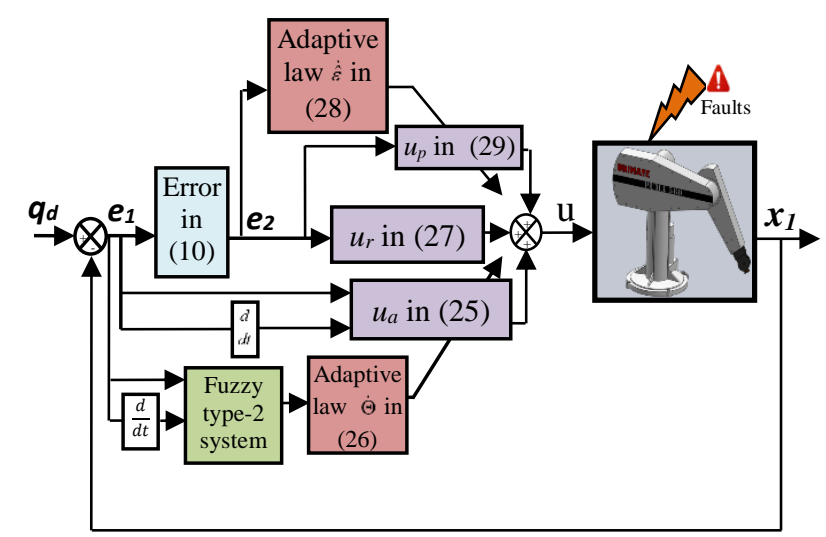

Figure. 2 Proposed adaptive control scheme 
to follow sinusoidal reference trajectory. In Test 2, a cycloidal reference trajectories are considered to the three joints of PUMA 560 robot, in addition these two tests contains a comparative study with precedent control method proposed in literature. For each simulation test, the input variable $\left(e_{1,2 m+1}, \dot{e}_{1,2 m+1}\right)$ of the fuzzy type-2 system in Eq. (25) are decomposed into five linguistic variables on the normalized intervals $[-1,1]$ with five type- 2 Gaussian membership functions.

\subsection{Test 1:}

In this first simulation, the robot is supposed to track the following desired trajectory:

$$
\left\{\begin{array}{l}
q_{1 d}=\cos \left(\frac{8}{5 \pi} t\right)-1 \\
q_{2 d}=\cos \left(\frac{8}{5 \pi} t+\frac{\pi}{2}\right) \\
q_{3 d}=\sin \left(\frac{8}{5 \pi} t+\frac{\pi}{2}\right)-1
\end{array}\right.
$$

To verify the effectiveness of the proposed fault tolerant control, we provide a sudden defect $U_{0}=$ $\left[\begin{array}{lll}350 & 360320\end{array}\right]^{T} \mathrm{~N} . \mathrm{m}$ at $t=12 \mathrm{sec}$ in the three actuators in same time. In addition, the mass of payload $m_{0}$ applied at the end of the third joint is varied from $10 \mathrm{~kg}$ to $2 \mathrm{~kg}$ in the period of $25 \mathrm{sec}$ as depicted in Fig.3. The initial angle displacements are $q\left((0)=\left[\begin{array}{llll}17.2 & 14.3 & 17.2\end{array}\right]^{T}\right.$ deg. The simulation are effectuated for proving the capability of the proposed control approach in faulty condition and compared with other control strategies available in literature such as [19, 25 and 27]. Numerical simulation results are depicted in Figures 3-6. The positions of joints 1, 2 and 3 are presented in figure 4 . Tracking error signals are illustrated in Figure 5. It is remarked that good trajectory tracking are given by utilizing the proposed control strategy. To better prove the higher performances in faulty condition of the proposed control strategy, three controllers proposed in [19, 25 and 27] are considered in our simulation for the aim of comparison. The real trajectories along joints 1,2 and 3 positions, corresponding to the control method proposed in [19, 25 and 27] are deviate from their desired values as shown in figure 4 , which explicate the insufficiency of this control strategy in faulty condition. The proposed controller has less tracking errors in compared to the three other controllers as presented in Figures 5 and 6 presents the control inputs, which on can distinctly view that the control torques is smooth.

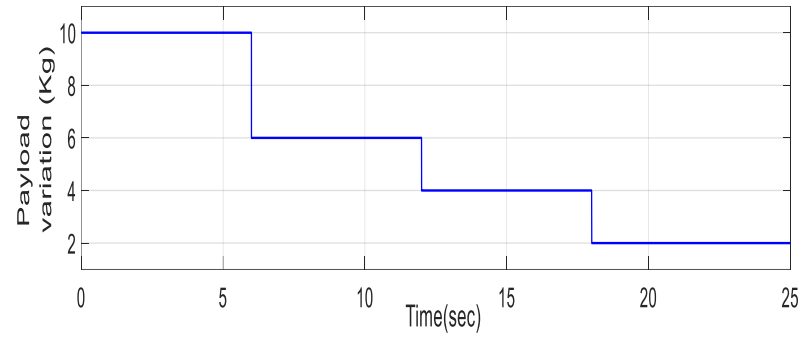

Figure. 3 Payload variation (Test 1)
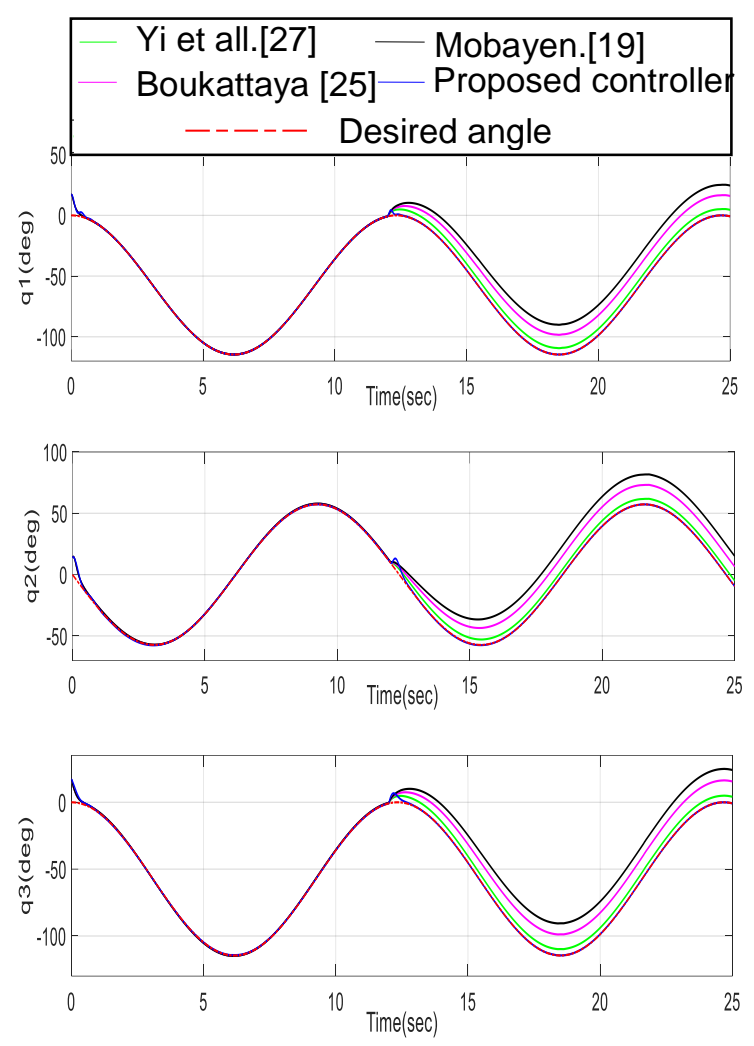

Figure. 4 Joint angles tracking responses (Test 1)

\subsection{Test 2:}

In this test, cycloidal function signals are utilized as the reference performance. The three joints desired trajectories are chosen as:

$$
\begin{aligned}
& q_{d i}(t)= \\
& \left\{\begin{array}{l}
q_{d i}(0)+\frac{D_{i}}{2 \pi}\left[2 \pi \frac{t}{t_{f}}-\sin \left(2 \pi \frac{t}{t_{f}}\right)\right] \\
\text { for } 0 \leq t \leq t_{f} \\
q_{d i}\left(t_{f}\right) \text { for } t>t_{f} \text { with } i=\{1,2,3\}
\end{array}\right.
\end{aligned}
$$

Where: $D_{i}=q_{d i}\left(t_{f}\right)-q_{d i}(0)$ and $t_{f}$ is the final time of robot motion. 
In order to check the capability of the proposed
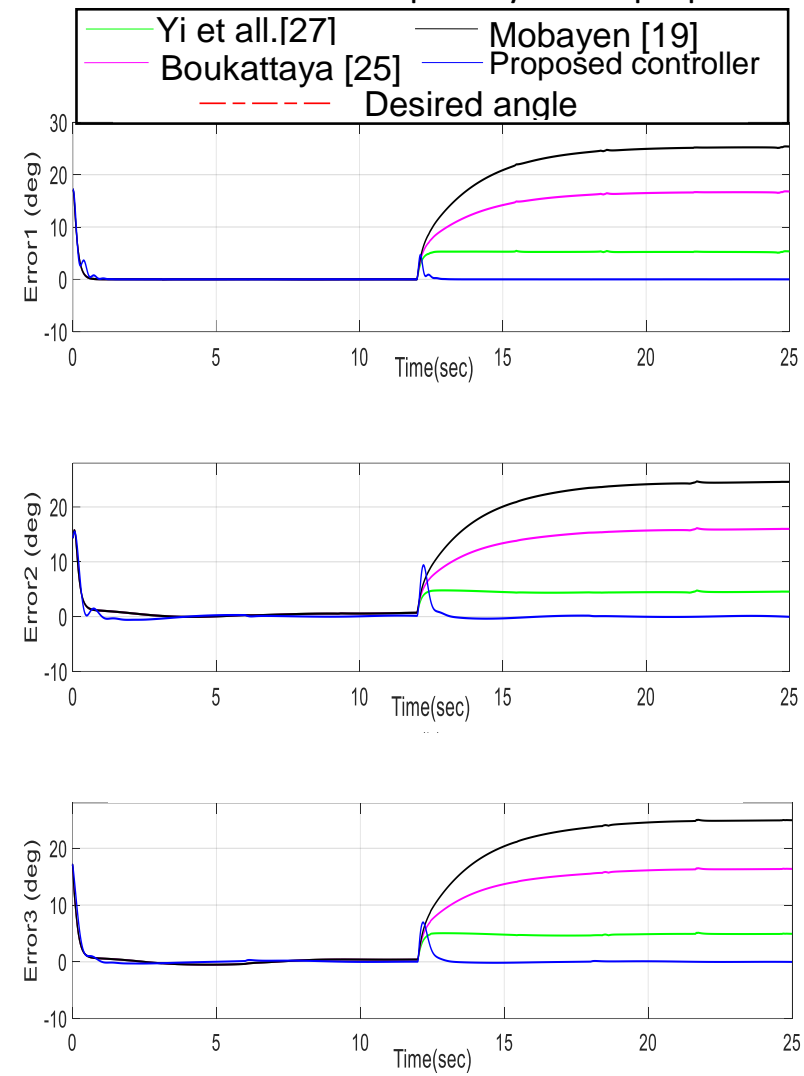

Figure .5 Joint angles tracking errors (Test 1)
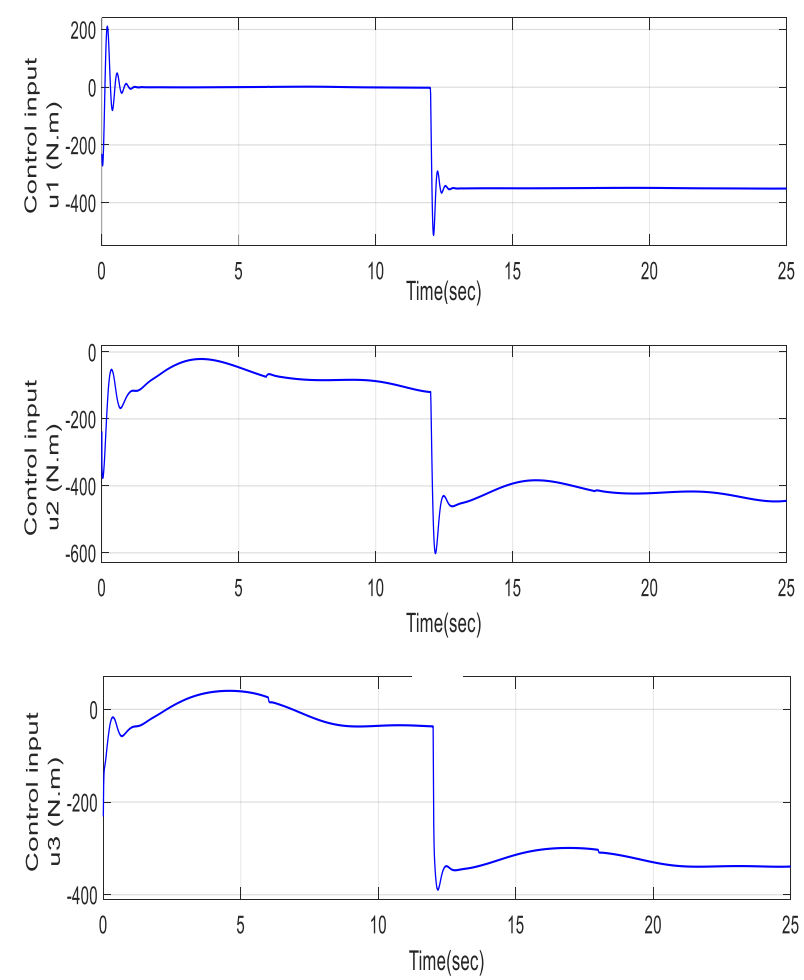

Figure. 6 Control input signal of the proposed controller (Test 1)

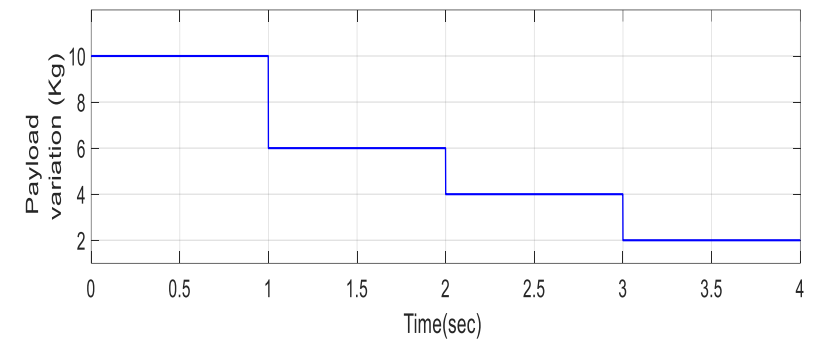

Figure. 7 Payload variations (Test 2)

control to against actuator faults, we furnish the following abrupt defect:

$$
U_{0}= \begin{cases}150 N \cdot m & t=2 \mathrm{sec} \\ 120 \mathrm{~N} \cdot m & t=2 \mathrm{sec} \\ 230 \mathrm{~N} \cdot \mathrm{m} & t=3 \mathrm{sec}\end{cases}
$$

Payload mass $m_{0}$ varies in the interval from $10 \mathrm{~kg}$ to $2 \mathrm{~kg}$ and is depicted in figure 7. The initial conditions of the three joints are $q((0)=[-54-$ $130125]^{T} \mathrm{deg}$. Three joints trajectory tracking performance are presented in figure 8 and figure 9 indicate the joint tracking error for joints 1,2 , and 3 , respectively. It is noted that the tracking error in faulty condition of the proposed control is the smallest in compared to the proposed control in [19, $25,27]$. The position for joints 1,2 , and 3 obtained by the control strategy proposed in $[19,25,27]$ are deflected from their reference trajectory as shown in Fig.8, which indicate the incapability of this control method in faulty operation.

\section{Performance comparison with existing adaptive fuzzy type-2 backstepping control (AFT2BC)}

In this section a quantitative comparison will be addressed in order to well illustrate the comparison between four control strategies based on adaptive fuzzy type-2 backstepping, for this purpose an IAE (integral absolute error), ISE (integral square error), IATE (integral time absolute error) and ISV. The IAE, ISE and IATE are utilized as error tracking measured and ISV denotes energy consumption. The IAE, ISE, IATE and ISV criteria are defined as:

$$
I A E=\int_{0}^{t_{f}}\left|e_{1}(t)\right| d t
$$

$$
I S E=\int_{0}^{t_{f}} e_{1}^{2}(t) d t
$$



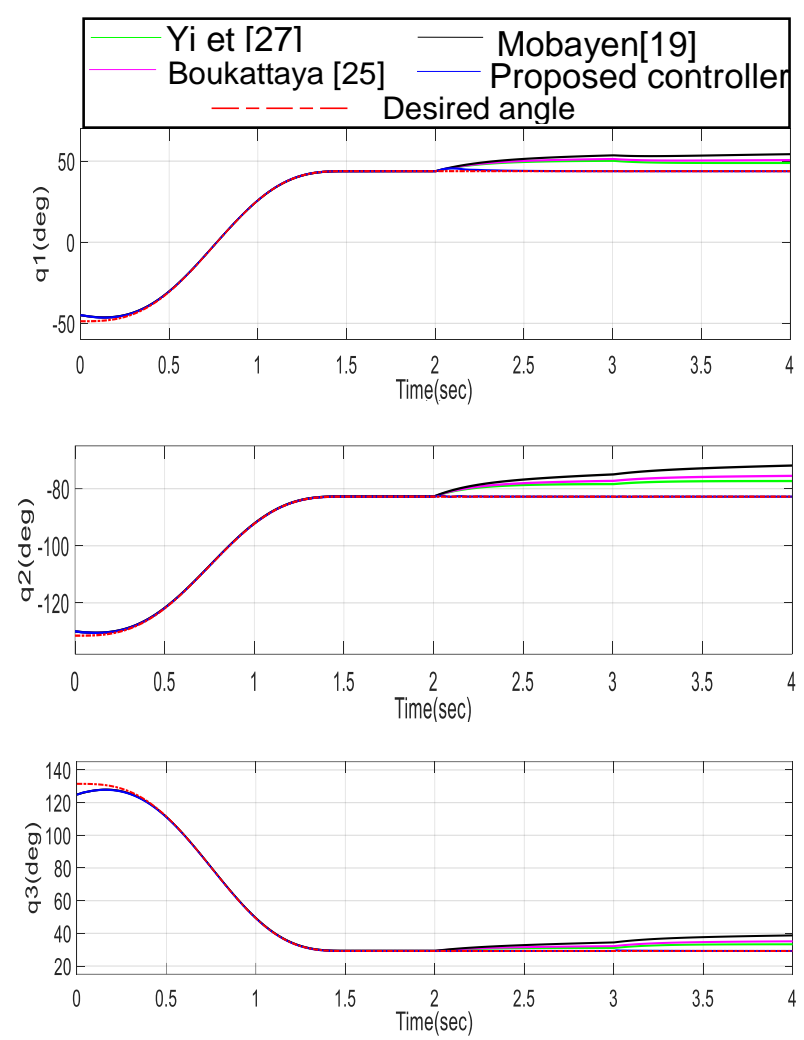

Figure.8 Joint angles tracking responses (Test 2)
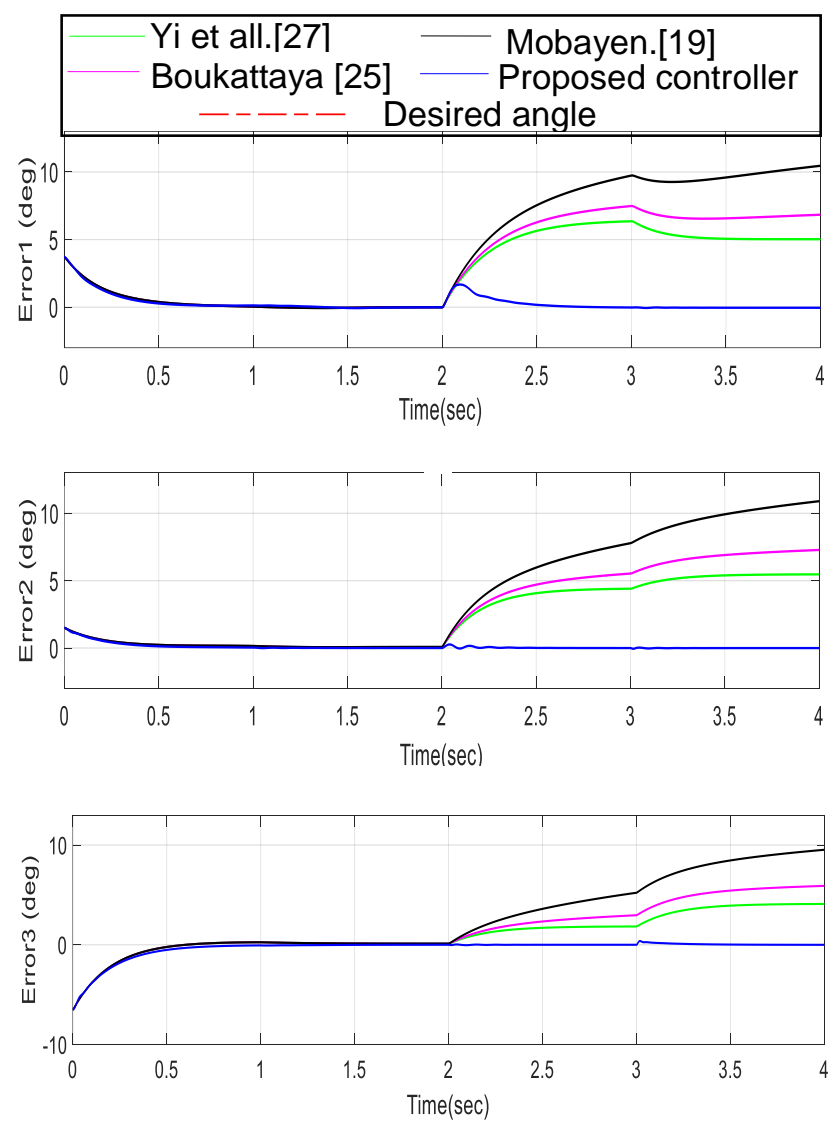

Figure. 9 Joint angles tracking errors (Test 2)
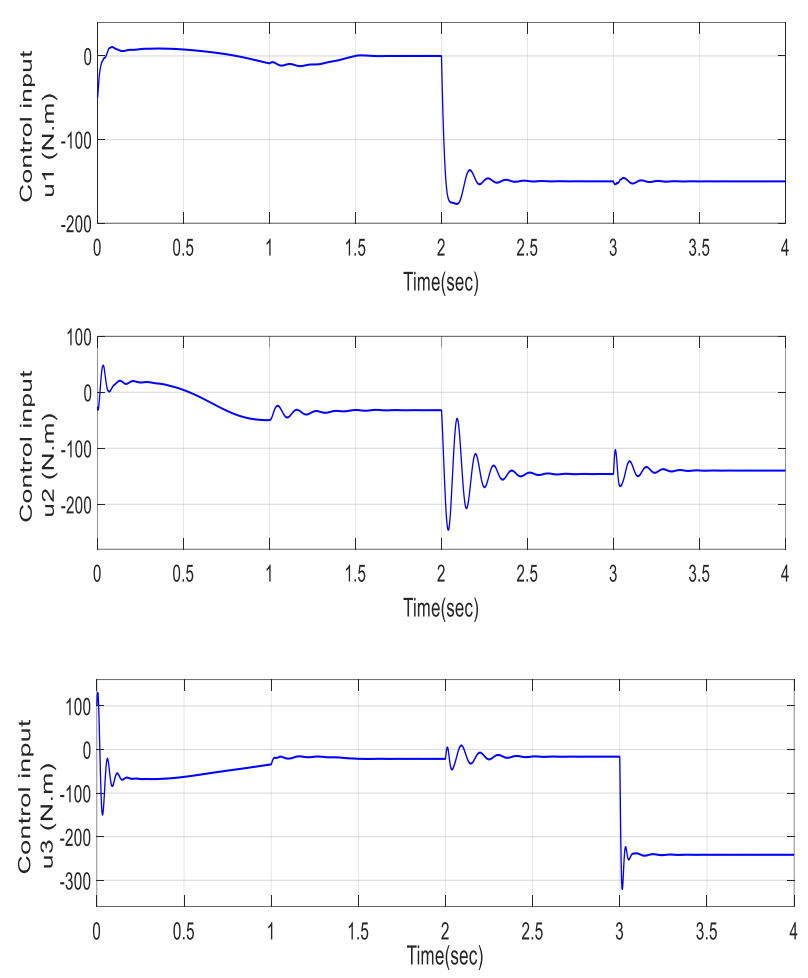

Figure.10 Control input signal of the proposed controller (Test 2)

Table 1. Quantitative comparison under external disturbances, payload variation and actuator faults with existing adaptive fuzzy type- 2 backstepping

\begin{tabular}{|c|c|c|c|c|c|}
\hline \multicolumn{2}{|c|}{$\begin{array}{l}\text { Control } \\
\text { scheme }\end{array}$} & $\begin{array}{l}\text { AFT2BC } \\
\text { proposed } \\
\text { in [52] }\end{array}$ & $\begin{array}{l}\text { AFT2BC } \\
\text { proposed } \\
\text { in [53] }\end{array}$ & $\begin{array}{l}\text { AFT2BC } \\
\text { proposed } \\
\text { in [33] }\end{array}$ & $\begin{array}{l}\text { Proposed } \\
\text { AFT2BC } \\
\text { strategy }\end{array}$ \\
\hline \multirow{3}{*}{ IAE } & $\begin{array}{l}\text { Joint } \\
1\end{array}$ & 19.53 & 12.61 & 57.99 & 0.5323 \\
\hline & $\begin{array}{l}\text { Joint } \\
2\end{array}$ & 2.45 & 3.14 & 16.94 & 0.2155 \\
\hline & \begin{tabular}{|l} 
Joint \\
3 \\
\end{tabular} & 8.15 & 19.55 & 21.85 & 1.016 \\
\hline \multirow{3}{*}{ ISE } & $\begin{array}{l}\text { Joint } \\
1\end{array}$ & 23.14 & 65.93 & 2.07 & 0.9763 \\
\hline & $\begin{array}{l}\text { Joint } \\
2\end{array}$ & 2.27 & 3.83 & 210.51 & 0.1484 \\
\hline & \begin{tabular}{|l|} 
Joint \\
3 \\
\end{tabular} & 30.95 & 318.87 & 558.25 & 3.233 \\
\hline \multirow{3}{*}{ IATE } & $\begin{array}{l}\text { Joint } \\
1\end{array}$ & 19.53 & 34.41 & 189.31 & 0.122 \\
\hline & \begin{tabular}{|l|} 
Joint \\
2 \\
\end{tabular} & 5.61 & 7.76 & 56.78 & 0.08 \\
\hline & \begin{tabular}{|l} 
Joint \\
3 \\
\end{tabular} & 19.53 & 34.41 & 189.31 & 0.122 \\
\hline \multirow{3}{*}{ ISV } & \begin{tabular}{|l} 
Joint \\
1 \\
\end{tabular} & 5.61 & 7.76 & 56.78 & 0.08 \\
\hline & \begin{tabular}{|l|} 
Joint \\
2 \\
\end{tabular} & 19.53 & 34.41 & 189.31 & 0.122 \\
\hline & $\begin{array}{l}\text { Joint } \\
3\end{array}$ & 5.61 & 7.76 & 56.78 & 0.08 \\
\hline
\end{tabular}




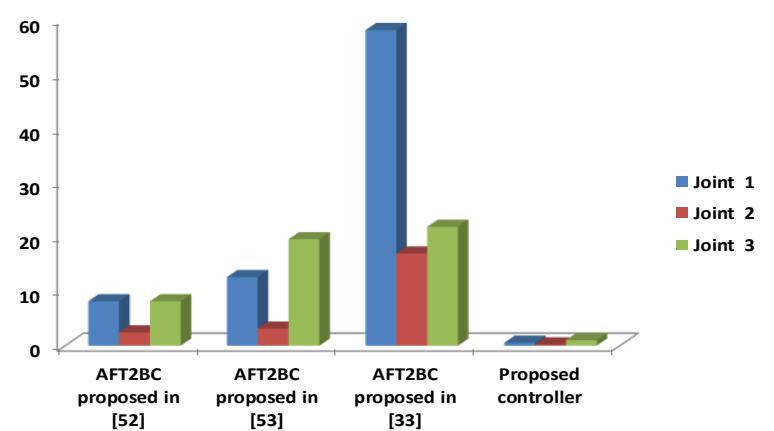

(a)

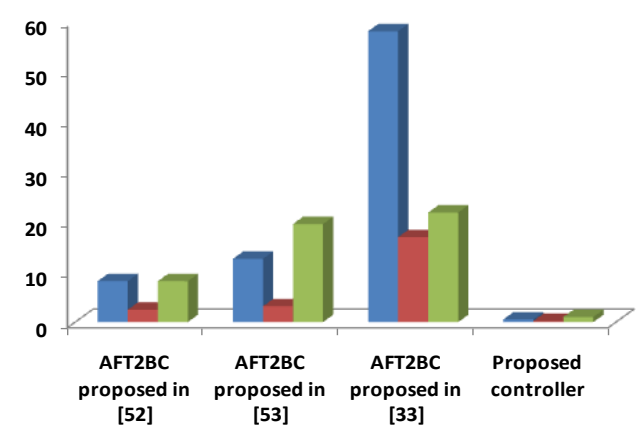

(b)

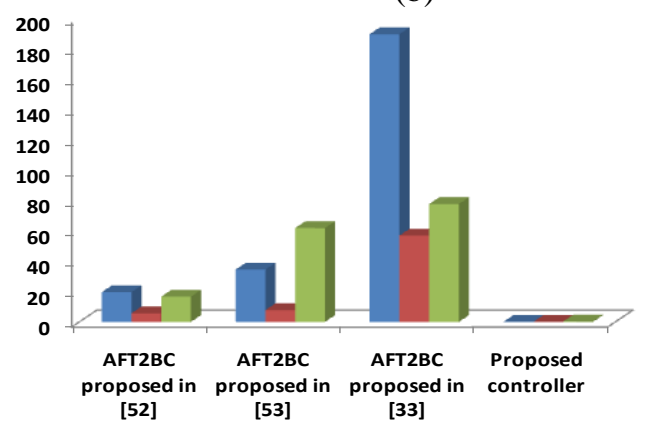

(c)

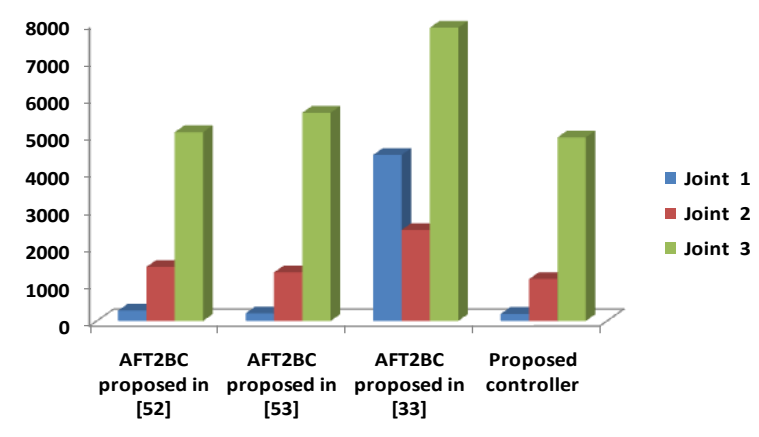

(d)

Figure. 11 Histogram of performance indices: (a) IAE, (b) ISE, (c) IATE and (d) ISV

$$
\begin{gathered}
I A T E=\int_{0}^{t_{f}} t\left|e_{1}(t)\right| d t \\
I S V=\int_{0}^{t_{f}} u_{1}^{2}(t) d t
\end{gathered}
$$

From the quantitative comparison results presented in Table.1, and figure 11. It is confirmed that performance indices (IAE, ISE, and IATE) values of the proposed AFT2BC strategy are lower compared with the existing control $[33,52,53]$. In addition, comparing the control inputs (energy consumption), it is remarked that the proposed control strategy also gives superior control input performance as shown in Table.1, and figure 11.

\section{Conclusion}

In this work, a robust type- 2 adaptive control has been developed for trajectory tracking of an industrial 3 -DOF manipulator robot in faulty condition. The adaptation consists of online adjustments of fuzzy type- 2 parameters by exploiting Lyapunov stability concepts.

In addition, the proposed control strategies contain an additive control term with adaptive gain in order to compensate the estimations errors and of actuator faults. The simulation results of the proposed control strategy demonstrate the efficiency to give a small tracking error in existence payload variation and actuator faults. It can also be concluded the proposed control strategy guaranty a best performances in defectively operation compared to the precedent control strategy proposed in [19, 25 and 27]. In addition the developed control algorithm does not require a priori knowledge about dynamic model. Therefore, the proposed controller can operate in faulty condition such as with model uncertainties and external disturbances.

The numerical simulations results show that a satisfactory tracking precision are obtained by using the proposed adaptive fuzzy type- 2 backstepping. Finally, as future work, will be focused on the practical implementation of the proposed control.

\section{References}

[1] L. M. Capisani, A. Ferrara, and L. Magnani, "Second order sliding mode motion control of rigid robot manipulators", In: Proc. of the 46th IEEE Conference on Decision and Control, pp. 12-14, 2007.

[2] P. Rocco, "Stability of PID control for industrial robot arms", IEEE Trans Robot Autom, Vol. 12, No. 4, pp. 606-614, 1996.

[3] E. Kim, "Output feedback tracking control of robot manipulators with model uncertainty via adaptive fuzzy logic", IEEE Trans Fuzzy Sys, Vol. 12, No. 3, pp. 368-378, 2004.

[4] W. He and Y. Dong, "Adaptive fuzzy neural network control for a constrained robot using impedance learning", IEEE Trans Nerural Netw Lear, Vol. 29, No. 4, pp. 1174-1186, 2018. 
[5] K. Kreutz, "On manipulator control by exact linearization", IEEE Trans Automat Control, Vol. 34, No. 7, pp. 763-770, 1989.

[6] P. Poignet and M. Gautier, "Nonlinear model predictive control of a robot manipulator", In: Proc. of the 6th international workshop on advanced motion control, pp. 401-406, 2000.

[7] F. Lin and R. D. Brandt, "An optimal control approach to robust control of robot manipulators", IEEE Transactions on Robotics and Automation, Vol. 14, No. 1, pp. 69-77 1998.

[8] J. J. Slotine and S. S. Sastry, "Tracking control of non-linear systems using sliding surfaces, with application to robot manipulators", International journal of control, Vol. 38 No. 2, pp. 465-492, 1983.

[9] SI. Han and J. Lee "Finite-time sliding surface constrained control for a robot manipulator with an unknown dead zone and disturbance", ISA Trans, Vol. 65, pp. 307-318, 2016.

[10] L. Zhao, H. Cheng, and T. Wang, "Sliding mode control for a two-joint coupling nonlinear system based on extended state observer", ISA Trans,Vol. 73, pp. 130-140, 2018.

[11] H. Benadda, B. Bourahla, and A. Mansouri, "Robust observer based backstepping controller for robot manipulator", In: Proc. of the 8th International Conference on Modelling, Identification and Control (ICMIC), pp. 91-96, 2016.

[12] M. Zhu and Y. Li, "Decentralized adaptive fuzzy sliding mode control for reconfigurable modular manipulators", International Journal of Nonlinear Control, Vol. 20, No. 4, pp. 472-488, 2010.

[13] Q. P. Ha, D. C. Rye, and H. F. Durrant-Whyte, "Fuzzy moving sliding mode control with application to robotic manipulators", Automatica, Vol. 35, No. 4, pp. 607-616, 1999.

[14] E. M. Jafarov, M. N. A. Parlakci, and Y. Istefanopulos, "A new variable structure PIDcontroller design for robot manipulators", IEEE Transactions on Control Systems Technology, Vol. 13, No. 1, pp. 122-130, 2005.

[15] S. Islam and X. P. Liu, "Robust Sliding Mode Control for Robot Manipulators", IEEE Transactions on Industrial Electronics, Vol. 58, No. 6, pp. 2444-2453, 2011.

[16] Z. Man, AP. Paplinski, and HR. Wu, "A robust MIMO terminal sliding mode control scheme for rigid robotic manipulators", IEEE Trans Automat Control, Vol. 39, No. 12, pp. 24642490, 1994.

[17] M. Van, SS. Ge, and H. Ren, "Finite time fault tolerant control for robot manipulators using time delay estimation and continuous nonsingular fast terminal sliding mode control", IEEE Trans Cybern, Vol. 47, No. 7, pp. 16811693, 2017.

[18] L. Wang, T. Chai, and L. Zhai, "Neuralnetwork-based terminal sliding-mode control of robotic manipulators including actuator dynamics", IEEE Trans Ind Electron, Vol. 56, No. 9, pp. 3296-3304, 2009.

[19] S. Mobayen, F. Tchier, and L. Ragoub, "Design of an adaptive tracker for n-link rigid robotic manipulators based on super-twisting global nonlinear sliding mode control", International journal Systems Science, Vol. 48, No. 9, pp. 1990-2002, 2017.

[20] CS. Jeong, JS. Kim, and SI. Han, "Tracking error constrained super-twisting sliding mode control for robotic systems", International Journal of Control Automatic Systems, Vol. 16, No. 2, pp. 804-814, 2018.

[21] A. Goel and A. Swarup, "MIMO uncertain nonlinear system control via adaptive high-order super twisting sliding mode and its application to robotic manipulator", Journal of Control Autom Elect Sys, Vol. 28, No. 1, pp. 36-49, 2017.

[22] K. Lochan, BK. Roy, and B. Subudhi, "Robust tip trajectory synchronisation between assumed modes modelled two-link flexible manipulators using second-order PID terminal SMC", Robot Auton Sys, Vol. 97, pp. 108-124, 2017.

[23] S. Ding, S. Li, and WX. Zheng, "New approach to second-order sliding mode control design", IET Control Theory Appl, Vol. 7, No. 18, pp. 2188-2196, 2013.

[24] X. Tang, CK. Tang, and H. Li, "A backstepping robust control method for free-floating space robot system with dual-arms", In: Proc. of the IEEE International Conference on Robotics and Biomimetics, pp. 761-765, 2011.

[25] M. Boukattaya, N. Mezghani, and T. Damak, "Adaptive nonsingular fast terminal slidingmode control for the tracking problem of uncertain dynamical systems", ISA Trans, Vol. 77, pp. 1-19, 2018.

[26] S. Mondal and C. Mahanta, "Adaptive second order terminal sliding mode controller for robotic manipulators", Journal of The Franklin Institute, Vol. 351, No. 4, pp. 2356-2377, 2014.

[27] Y. Shanchao and Z. Junyong, "Adaptive secondorder fast nonsingular terminal sliding mode control for robotic manipulators", ISA Trans, Vol. 90, pp. 41-51, 2019.

[28] H. Qinglei, X. Liang, and Z. Aihua, "Adaptive backstepping trajectory tracking control of robot 
manipulator", Journal of The Franklin Institute, Vol. 349, pp. 1087-1105, 2012.

[29] A. F Amer, A. S. Elsayed, and M. E. Wael, "Adaptive fuzzy sliding mode control using supervisory fuzzy control for 3 DOF planar robot manipulators", Applied Soft Computing, Vol. 11, pp. 4943-4953, 2011.

[30] H. V. A Truong, D. T. Tran, X. D. To, K. K. Ahn, and M. Jin, "Adaptive Fuzzy Backstepping Sliding Mode Control for a 3-DOF Hydraulic Manipulator with Nonlinear Disturbance Observer for Large Payload Variation", Applied Sciences, Vol. 9, No. 16, 3290, 2019.

[31] J. Zhou and Q. Zhang, "Adaptive Fuzzy Control of Uncertain Robotic Manipulator", Mathematical Problems in Engineering, Vol. 18, 2018.

[32] W. Min and Q. Liu, "An improved adaptive fuzzy backstepping control for nonlinear mechanical systems with mismatched uncertainties", Automatika, Vol. 60, No. 1, pp. 1-10, 2019.

[33] X. Chen and W. W. Tan, "Tracking control of surface vessels via fault-tolerant adaptive backstepping interval type-2 fuzzy control", Ocean Engineering, Elsevier, Vol. 70, pp. 97109, 2013.

[34] S. Zeghlache, A. Djerioui, L. Benyettou, T. Benslimane, H. Mekki, and A. Bouguerra, "Fault tolerant control for modified quadrotor via adaptive type-2 fuzzy backstepping subject to actuator faults", ISA Transactions, Vol. 95, pp. 330-345, 2019.

[35] A. A. Jafari, S. M. A. Mohammadi, and M. H. Naseriyeh, "Adaptive type-2 fuzzy backstepping control of uncertain fractional-order nonlinear systems with unknown dead-zone", Applied Mathematical Modelling, Vol. 69, pp. 506-532, 2019.

[36] Q. D. Le and H. J. Kang, "Finite-Time FaultTolerant Control for a Robot Manipulator Based on Synchronous Terminal Sliding Mode Control", Appl. Sci., Vol. 10, pp. 1-15, 2020.

[37] A. A. G. Siqueiraa, M. H. Terrab, and C. Buosib, "Fault-tolerant robot manipulators based on output-feedback Hळ controllers", Robotics and Autonomous Systems, 2007.

[38] B. Xiao, S. Yin, and H. Gao, "Reconfigurable Tolerant Control of Uncertain Mechanical Systems With Actuator Faults: A Sliding Mode Observer-Based Approach", IEEE Transactions on Control Systems Technology, Vol. 26, pp. 1249-1258, 2018.

[39] H. Huang, W. He, J. Li, B. Xu, C. Yang, and W. Zhang, "Disturbance Observer-Based Fault-
Tolerant Control for Robotic Systems With Guaranteed Prescribed Performance", IEEE Transactions on Cybernetics, pp. 1-12, 2020.

[40] M. Van, X. P. Do, and M. Mavrovouniotis, "Self-tuning fuzzy PID-nonsingular fast terminal sliding mode control for robust fault tolerant control of robot manipulators", ISA Trans, Vol. 96, pp. 60-68, 2020.

[41] S. Y. Yi and M. J. Chung, "A robust fuzzy logic controller for robot manipulators with uncertainties", IEEE Transactions on Systems, Man, and Cybernetics, Part B (Cybernetics), Vol. 4, pp. 706-713, 1997.

[42] J. L. Meza, V. Santibanez, R. Soto, and M. A. Llama, "Fuzzy Self-Tuning PID Semiglobal Regulator for Robot Manipulators", IEEE Transactions on Industrial Electronics, Vol. 6, pp. 2709-2717, 2012.

[43] J. Tavoosi and F. Mohammadi, "A New Type-II Fuzzy System for Flexible-Joint Robot Arm Control", In: Proc. of the IEEE of the 6th International Conference on Control, Instrumentation and Automation (ICCIA), pp. 14, 2019.

[44] J. Beata, "Fuzzy logic controller for robot manipulator control system", In: Proc. of the IEEE international conference on Applications of Electromagnetics in Modern Techniques and Medicine (PTZE), pp. 77-80, 2018.

[45] Z. Andrew and J. Samuel, "A review of control algorithms for autonomous quadrotors", open journal of applied science, Vol. 4, pp. 547-556, 2014.

[46] P. J. Gaidhane, M. J. Nigam, A. Kumar, and P. M. Pradhan, "Design of interval fuzzy type-2 precompensated PID controller applied to twoDOF robotic manipulator with variable payload", ISA Trans, Vol. 89, pp. 169-185, 2019.

[47] R. Hayat, M. Leibold, and M. Buss, "RobustAdaptive Controller Design for Robot Manipulators Using the Hoo Approach", IEEE Access, Vol. 6, pp. 51626-51639, 2018.

[48] Z. Yu and G. Cai, "Robust adaptive control of a 6-DOF space robot with flexible panels", International Journal of Dynamics and Control, Vol. 7, pp. 1370-1378, 2019.

[49] A. Boubakir, "Méthodes de commande par mode de glissement appliquées au bras manipulateur et au système hydraulique CE105 à réservoirs couplés", Magister Thesis, 2007.

[50] Y. Fouad, B. Omar, H. Mustapha, and R. Nassim, "Observer-based Adaptive Fuzzy Backstepping Tracking Control of Quadrotor Unmanned Aerial Vehicle Powered by Li-ion Battery", 
Journal of Intelligent \& Robotic Systems, Vol. 84, pp. 179-197, 2016.

[51] N. Bounar, A. Boulkroune, F. Boudjema, M. M'Saad, and M. Farza, "Adaptive fuzzy vector control for a doubly-fed induction motor", Neurocomputing, Vol. 151, pp. 756-769, 2015.

[52] L. Yi-Min, Y. Yang, and L. Li, "Adaptive Backstepping Fuzzy Control Based on Type-2 Fuzzy System", Journal of Applied Mathematics, Vol. 12, 2012.

[53] F. Yang, R. Yuan, J. Yi, G. Fan, and X. Tan, "Backstepping Based Type-2 Adaptive Fuzzy Control for a Generic Hypersonic Flight Vehicle", In: Proc. of the 2013 Chinese Intelligent Automation Conference, Vol. 254, pp. 169-177, 2013.

\section{Appendix A}

First the following variables are defined by:

$$
\begin{cases}c_{i}=\cos \left(q_{i}\right), & c_{i j}=\cos \left(q_{i}+q_{j}\right) \\ s_{i}=\sin \left(q_{i}\right), & s_{i j}=\sin \left(q_{i}+q_{j}\right)\end{cases}
$$

The inertia matrix is given by:

$$
\begin{aligned}
& M(q)= \\
& {\left[\begin{array}{ccc}
I_{1}+I_{2} c_{23}^{2}+I_{2} c_{2}^{2}+I_{4} c_{2} c_{23} & I_{5} s_{23}+I_{6} s_{23} & I_{5} s_{23} \\
I_{5} s_{23}+I_{6} s_{2} & I_{7}+I_{4} c_{3} & I_{8}+0.5 I_{4} c_{3} \\
I_{5} s_{23} & I_{8}+0.5 I_{4} c_{3} & I_{9}
\end{array}\right]}
\end{aligned}
$$

Where:

$$
\begin{aligned}
& I_{1}=I_{y y 1}+I_{x x 2}+m_{2} d_{2}\left(d_{2}+e\right)+m_{3} d_{2}^{2}+I_{x x 3} \\
& +I_{x x t}+\cdots m_{t} d_{2}^{2}+I_{M 1} \\
& I_{2}=I_{y y 3}-I_{x x 3}+I_{y y t}-I_{x x t}+m_{t} l_{3}^{2} \\
& I_{3}=I_{y y 2}-I_{x x 2}+m_{3} l_{2}^{2}+m_{t} l_{2}^{2} \\
& I_{4}=m_{3} l_{2} l_{3}+2 m_{t} l_{2} l_{3} \\
& I_{5}=0.5 m_{3} l_{3} d_{2}+m_{t} l_{3} d_{2} \\
& I_{6}=0.5 m_{2} l_{2}\left(d_{2}+e\right)+m_{3} l_{2} d_{2} \\
& I_{7}=I_{z z 2}+I_{z z 3}+m_{3} l_{2}^{2}+I_{z z t}+m_{t}\left(l_{2}^{2}+l_{3}^{2}\right)+I_{M 2} \\
& I_{8}=I_{z z 3}+I_{z z t}+m_{t} l_{3}^{2}
\end{aligned}
$$

$I_{9}=I_{8}+I_{M 3}$

$I_{M i}(i=1, \ldots 3)$ are the inertias moments of the different motors.

$I_{x x t}, I_{y y t}, I_{z z t}$ Represents the total inertias moments relative to the main axes of the effector.

The state varying vector of gravity terms is obtained by:

$$
G(q)=\left[\begin{array}{c}
0 \\
-\left(m_{3} l_{2}+0.5 m_{2} l_{2}\right) g c_{2}-0.5 m_{3} l_{3} g c_{23} \\
-0.5 m_{3} l_{3} g c_{23}
\end{array}\right]
$$

The Jacobian matrix is defined as:

$$
\begin{aligned}
& J(q)= \\
& {\left[\begin{array}{ccc}
-s_{1}\left(l_{2} c_{2}+l_{3} c_{23}\right)-d_{2} c_{1} & -c_{1}\left(l_{2} s_{2}+l_{3} s_{23}\right) & -c_{1}\left(l_{3} s_{23}\right) \\
c_{1}\left(l_{2} c_{2}+l_{3} c_{23}\right)-d_{2} s_{1} & -s_{1}\left(l_{2} s_{2}+l_{3} s_{23}\right) & -s_{1}\left(l_{3} s_{23}\right) \\
0 & -\left(l_{2} c_{2}+l_{3} c_{23}\right) & -\left(l_{3} c_{23}\right)
\end{array}\right]}
\end{aligned}
$$

The matrix of coriolis and centrifugal forces is defined as follows:

$$
V_{m}(q, \dot{q}) \cdot \dot{q}=\left[\begin{array}{c}
V_{m 1} \\
V_{m 2} \\
V_{m 3}
\end{array}\right]
$$

Such as:

$$
\begin{aligned}
V_{m 1}=-\left(2 \left(I_{3} s_{2}\right.\right. & \left.c_{2}+I_{2} s_{23} c_{23}\right) \\
& \left.+I_{4}\left(c_{2} s_{23}+s_{2} c_{23}\right)\right) \dot{q}_{1} \dot{q}_{2} \\
& -\left(2 I_{2} s_{23} c_{23}+I_{4} c_{2} s_{23}\right) \dot{q}_{1} \dot{q}_{3} \\
& +\left(I_{6} c_{2}+I_{5} c_{23}\right) \dot{q}_{2}^{2}+\left(2 I_{5} c_{23}\right) \dot{q}_{2} \dot{q}_{3} \\
& +\left(I_{5} c_{23}\right) \dot{q}_{3}^{2} \\
V_{m 2}=\left(I_{3} c_{2} s_{2}\right. & +I_{2} c_{23} s_{23} \\
& \left.+0.5 I_{4}\left(s_{2} c_{23}+c_{2} s_{23}\right)\right) \dot{q}_{1}^{2} \\
& -\left(I_{4} s_{3}\right) \dot{q}_{2} \dot{q}_{3}-\left(0.5 I_{4} s_{3}\right) \dot{q}_{3}^{2} \\
V_{m 3}=\left(I_{2} s_{23} c_{23}\right. & \left.+0.5 I_{4} c_{2} s_{23}\right) \dot{q}_{1}^{2}+\left(0.5 I_{4} s_{3}\right) \dot{q}_{2}^{2}
\end{aligned}
$$

- Masses of the different liaisons

Table 2. Masses of the different liaisons

\begin{tabular}{|c|l|l|}
\hline $\begin{array}{l}m_{2} \\
=17.40 \mathrm{Kg}\end{array}$ & $\begin{array}{l}m_{3} \\
=5.04 \mathrm{Kg}\end{array}$ & $m_{4}=0.82 \mathrm{Kg}$ \\
\hline$m_{5}=0.35 \mathrm{Kg}$ & $\begin{array}{l}m_{6} \\
=0.09 \mathrm{Kg}\end{array}$ & $\begin{array}{l}m_{t} \\
=m_{4}+m_{5}+m_{6}\end{array}$ \\
\hline
\end{tabular}


- Geometric parameters

Table 3. Geometric parameters

\begin{tabular}{|c|c|c|c|}
\hline$d_{2}=149.0$ & $l_{2}=431$. & $l_{3}=433.07$ & $e=1$ \\
$9 \mathrm{~mm}$ & $8 \mathrm{~mm}$ & $\mathrm{~mm}$ & $\mathrm{~mm}$ \\
\hline
\end{tabular}

- Inertias parameters

Table 4. Inertias parameters

\begin{tabular}{|c|c|c|c|c|}
\hline 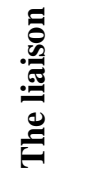 & $\begin{array}{c}I_{x x i} \\
{\left[K g m^{2}\right]}\end{array}$ & $\begin{array}{c}I_{y y i} \\
{\left[K \mathrm{gm}^{2}\right]}\end{array}$ & $\begin{array}{c}I_{z z i} \\
{\left[K^{2} m^{2}\right]}\end{array}$ & $\begin{array}{c}I_{M i} \\
{\left[K^{2} m^{2}\right]}\end{array}$ \\
\hline 1 & - & $350 \times 10^{-3}$ & - & 1.14 \\
\hline 2 & $130 \times 10^{-3}$ & $524 \times 10^{-3}$ & $539 \times 10^{-3}$ & 4.71 \\
\hline 3 & $192 \times 10^{-3}$ & $\begin{array}{c}15.4 \times 10^{-} \\
3\end{array}$ & $212 \times 10^{-3}$ & 0.83 \\
\hline 4 & $\begin{array}{c}1.30 \times 10^{-} \\
3\end{array}$ & $\begin{array}{c}1.80 \times 10^{-} \\
3\end{array}$ & $1.80 \times 10^{-3}$ & - \\
\hline 5 & $\begin{array}{c}0.30 \times 10^{-} \\
3\end{array}$ & $\begin{array}{c}0.30 \times 10^{-} \\
3\end{array}$ & $0.40 \times 10^{-3}$ & - \\
\hline 6 & $\begin{array}{c}0.04 \times 10^{-} \\
3\end{array}$ & $\begin{array}{c}0.15 \times 10^{-} \\
3\end{array}$ & $0.15 \times 10^{-3}$ & - \\
\hline $4+5+6$ & $\begin{array}{c}1.64 \times 10^{-} \\
3\end{array}$ & $\begin{array}{c}2.25 \times 10^{-} \\
3\end{array}$ & $2.35 \times 10^{-3}$ & - \\
\hline
\end{tabular}

